\title{
DETERMINATION OF RESIDUAL STRESS DISTRIBUTION IN HIGH STRENGTH ALUMINUM ALLOY AFTER EDM
}

\author{
Shahid Mehmood', Amir Sultan², Nazeer Ahmad Anjum', Waqas Anwar ${ }^{3}$, Zubair Butt ${ }^{2}$ \\ 1 University of Engineering and Technology Taxila, Mechanical Engineering Department, 47080 Taxila, Pakistan, \\ e-mail: shahid.mehmood@uettaxila.edu.pk, nazeer.anjum@uettaxila.edu.pk \\ 2 University of Engineering and Technology Taxila, Mechatronics Engineering Department, Chakwal Campus, \\ 48800 Chakwal, Pakistan, e-mail: amir.sultan@uettaxila.edu.pk, zubair.butt@uettaxila.edu.pk \\ 3 Institute of Space Technology, Engineering Research and Development Sector, 44000 Islamabad, Pakistan, \\ e-mail: waqasanwar_16@yahoo.com
}

Received: 2016.12.15

Accepted: 2017.02.01

Published: 2017.03.01

\begin{abstract}
Thermal energy produced by discrete and random electric sparks in electric discharge machining (EDM) melts surface material. A portion of this molten material is removed and the remaining material resolidified by rapid cooling in a hydrocarbon oil. The effect of repeated heating and cooling of the surface and sub surface material with complex temperature gradients results in residual stresses in machined parts. The aim of this investigation is to determine the distribution of residual stresses in the depth of machined material with respect to discharge current, most important electric parameter during EDM. It is well known that surface finish is dependent on discharge current. Therefore, investigations were carried out for smaller discharge current levels i.e. 3, 6, 9, 12 ampere. Hole-drill strain gauge method is used for the determination of residual stresses in the depth of material. For comparison purposes, residual stresses are also determined for conventionally turned specimens. This study provided quantitative analysis of the residual stresses for various discharge current in EDM which is a key parameter in deciding the service life of material.
\end{abstract}

Keywords: electric discharge machining, residual stresses, discharge current, aluminum alloy.

\section{INTRODUCTION}

A small portion of the molten surface material is removed and the residue material resolidified after each discharge. Due to rapid heating and cooling of the material, residual stresses are generated in the machined part which are known as "residual stresses" [23]. These stresses are of tensile nature and, if they become more than the yield strength of the material, it will cause surface cracking [21]. Residual stresses are recognized to be related to the thickness of white layer, which are greater at higher values of pulse current and pulse on time [12]. It is identified by Das [2] that near the surface, the magnitude of residual stresses increases significantly and disappear rapidly in the depth. It supports the idea that an increase in heat does not distress the depth of residual stress and their highest magnitudes near the surface. Bussu et al. [1] determined that crack propagation rate in aluminum alloy 2024-T6 is influenced by residual stresses, microstructure and hardness. Machining induced residual stresses are the primary cause for the deformation of aluminum plates [11].

Garc'ia Navas et al. [8] made a relative study of three machining processes; wire-EDM, hard turning and production grinding of AISI-01. Residual stresses could be divided in two main cat- 
egories. First category is macro residual stresses, which are easy to measure, existing between grains and could be represented by tensor. Second one is micro-residual stresses, which are not easy to determine, usually found around the flaws and defects. These stresses are represented by a scalar. Three types of Stress distributions, depending on the nature of machining process, could be generated, which was previously discussed by Parrish [8]. Where, Type-I represent stresses developed after abusive machining and type-III gives the pattern obtained by gentle machining and typeII is most undesirable; plastic deformation at the surface generates compressive stresses and a huge amount of heat under this layer produce high tensile stresses. EDM generates tensile stresses at the surface, whose value increases in depth and reaches maximum and then start to disappear gradually. This is close to the Type-II trend that is presented by Parrish as the worst stress distribution. This stress distribution may cause crack initiation at the early stage and fast crack propagation. It was identified that the finish parameter setting (low discharge energy) after rough machining caused a decrease in residual stresses [8].

Buelent Ekmekci et al. [5, 6] found that residual stresses depend on discharge energy and are independent of the pulse duration and current values, while finding residual stresses by removing Deemed layers by Electro chemical machining of plastic mold steel. It is also observed that residual stresses are tensile in nature, which are increasing in the depth and reaches its peak value within HAZ, and then fall rapidly to low value of compressive residual stresses. The intensity of surface cracks is independent of discharge energy and peak value of tensile residual stresses is close to the ultimate tensile strength of the material.

Among the different methods developed for this purpose, the hole-drilling and X-ray diffraction are widely employed for the quantitative residual stress analysis and are described in detail previously in 1980 [7, 17]. One of the popular techniques used on a large-scale basis for measuring residual stress is the hole-drilling method. A typical application of the hole-drilling method involves digging a small shallow hole in the sample. This material removal emphasized local stress and strain causes relaxations on the hole location [19]. The amount of strain relaxation is measured using specially strain gauge rosette.

X-ray methods have been used on a largescale method for measuring the residual stresses in crystalline materials. This method is nondestructive based on an assessment interplanar distances in distorted samples along different directions. However, in order to obtain information of these stresses below surface, it is essential to combine the means of removing a layer. Also limited to the size of the sample, it is difficult to analyze the residual stresses in the real cutting machine parts. X-rays penetrate the usually less than 20 microns in material and the way to do that is limited to determining residual stresses on the surface of the sample in a short depth [15].

A comprehensive literature review comprising behavior of residual stresses generated after conventional machining processes is presented by Gue et al. [9] in which mostly hard-to-cut metals are discussed. Rao et al. [22] determined residual stresses in Aluminum alloy 2014 T6 after EDM for the discharge current of 10 and 12 ampere, and this study was limited to surface. The aim of current research work is to determine the behavior of residual stresses in the depth of aerospace grade aluminum alloys 2024-T6 for four different discharge currents normally used for finish machining conditions during EDM.

\section{MATERIALS AND METHODS}

The material investigated for the study is an aerospace aluminum alloy 2024-T6. Chemical composition of the material is given in Table 1 . Mechanical properties of the selected material are determined by hardness and tensile tests, are provided in Table 2.

\section{EXPERIMENTAL}

Electric discharge machine of model Neur M 50 is used. The only varying parameter is discharge current. Four current levels 3, 6, 9 and 12 ampere are investigated. These discharge currents are mostly used in finish machining $[13,21]$. Other electrical parameters kept unchanged throughout the study are; Pulse-On time $60 \mu \mathrm{m}$, Pulse-Off time $4 \mu \mathrm{m}$, voltage 110 $\mathrm{V}$ and gap $5 \mu \mathrm{m}$. Kerosene oil is used as dielectric liquid. Both electrode and workpiece remain submerged during machining. Cylindrical workpiece of size $\phi 20 \times 22 \mathrm{~mm}$ is gripped by a clamp as shown in Figure 1. One-millimeter surface material is removed at all investigated discharge current levels. 
Table 1. Chemical composition of Al 2024 T6

\begin{tabular}{|c|c|c|c|c|c|c|c|}
\hline Element & $\mathrm{Cu}$ & $\mathrm{Si}$ & $\mathrm{Mg}$ & $\mathrm{Mn}$ & $\mathrm{Fe}$ & $\mathrm{Cr}$ & $\mathrm{Al}$ \\
\hline $\mathrm{Wt} \%$ & 3.70 & 0.19 & 1.22 & 0.73 & 0.41 & 0.07 & 93.68 \\
\hline
\end{tabular}

Table 2. Mechanical properties of Al 2024 T6

\begin{tabular}{|c|c|c|c|c|}
\hline Hardness & Yield Strength & Ult. Tensile Strength & Mod. Of Elasticity & $\%$ Elongation \\
\hline $140 \mathrm{Hv}$ & $520 \mathrm{MPa}$ & $600 \mathrm{MPa}$ & $72.4 \mathrm{GPa}$ & 11 \\
\hline
\end{tabular}

\section{Hole-drill set up}

The most commonly used technique for measuring residual stresses is the hole-drilling strain gage method defined in the standard E837 ASTM [18]. With this method, a rosette made up of three specially configured strain gauges is bonded to the surface of the specimen, and a shallow hole is drilled through the rosette center. As stresses are relaxed by hole drilling, the local difference in the strains are measured and the residual stresses are computed mathematically from these measurements. Detailed discussion of the theory and application of this technique are presented in Micro-Measurements Tech Note TN-503 [14]. The residual stresses are determined by the hole drill method by using RS 200 hole drill apparatus along with data-logger (P 3500 strain indicator). The equipment used for the purpose is shown in Figure 2.

\section{Computation of residual stresses}

The magnitude and distribution of the residual stresses below the surface was determined by using hole drilling method RS-200 [14]. The measurement of the residual stress by this method in accordance with the standard ASTM E 837 [4] consists of the following procedure:

- A special strain gage rosette (three grids) is fixed at the location at which residual stresses are to be determined.

- Each grid is joined with strain indicator and switch-and-balance unit. The RS-200 Milling Guide, shown in Figure 3(a), centered over the rosette. A precision hole is introduced at the center of rosette. The ratio of the drilled hole diameter (Do) to that of the gage circle (D) should be in the range of $0.3-0.5$ and the depth of the drilled blind hole should be equal to $0.4 \mathrm{D}$, A precision hole is introduced at the center of the rosette and after drilling a hole up to the desired depth, readings of the relaxed strain (residual strains) are recorded. Finally, residual stresses are computed according to the theoretical treatments. Three readings were noted from the strain indicator for each depth setting. After taking the three strain values, the principal stresses and their directions were computed by applying the following equations $1-3[16,24]$.

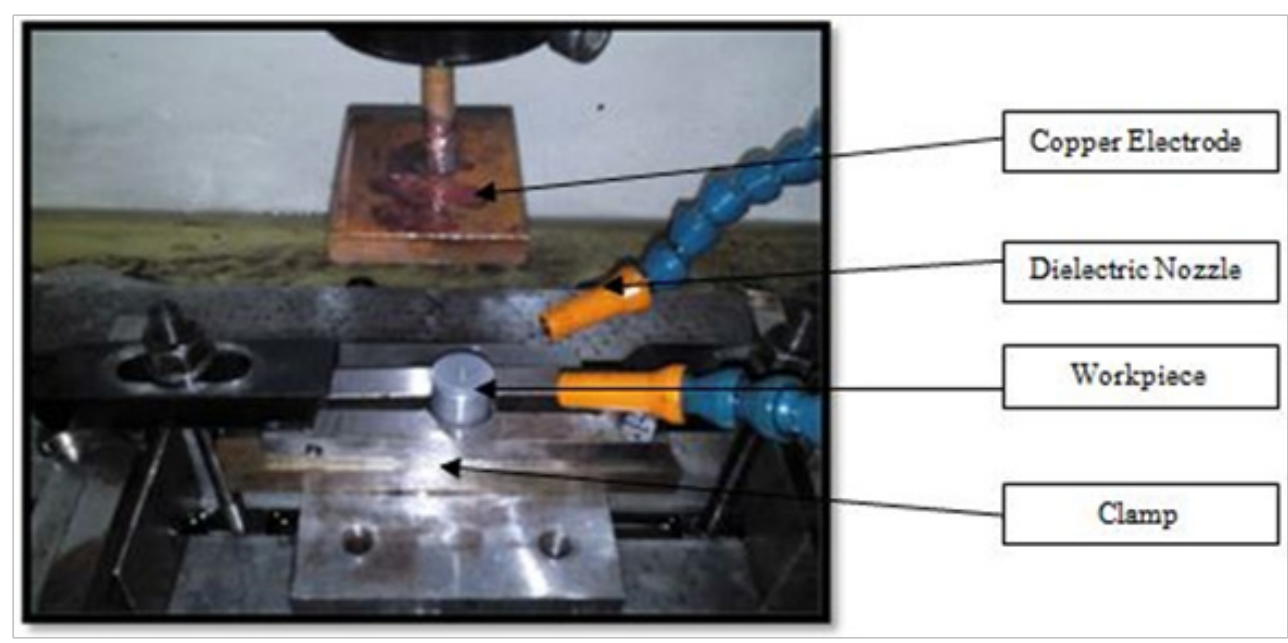

Fig. 1. Pictorial view of electric discharge machining setup 

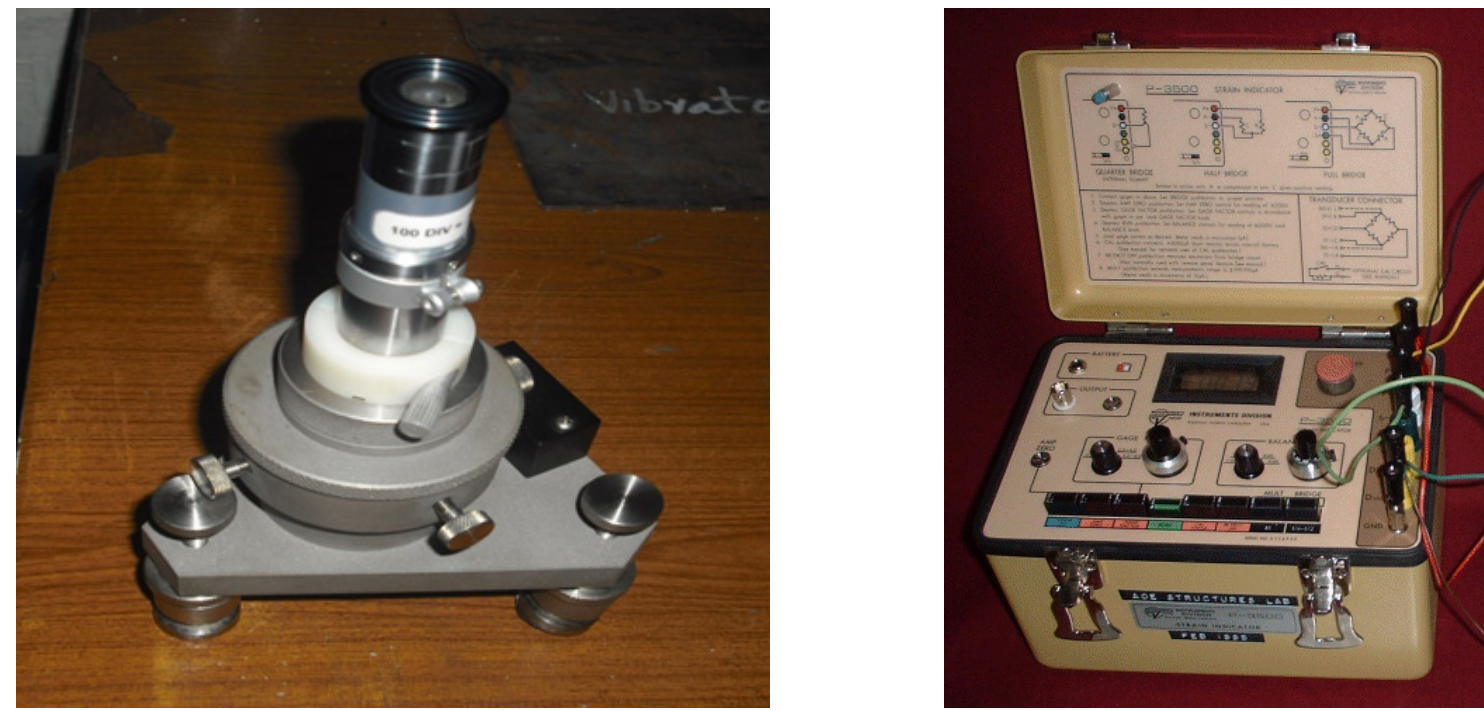

Fig. 2. Hole-drilling apparatus used for determination of residual stresses below the surface at different depths: left - milling guide, right - data logger

$$
\begin{gathered}
\sigma_{\max }=\frac{\varepsilon_{1}+\varepsilon_{3}}{4 A}-\frac{\sqrt{2}}{4 B} \sqrt{\left(\varepsilon_{1}-\varepsilon_{2}\right)^{2}+\left(\varepsilon_{2}-\varepsilon_{3}\right)^{2}} \\
\sigma_{\min }=\frac{\varepsilon_{1}+\varepsilon_{3}}{4 A}+\frac{\sqrt{2}}{4 B} \sqrt{\left(\varepsilon_{1}-\varepsilon_{2}\right)^{2}+\left(\varepsilon_{2}-\varepsilon_{3}\right)^{2}} \\
\tan 2 \alpha=\frac{\varepsilon_{1}-2 \varepsilon_{2}+\varepsilon_{3}}{\varepsilon_{3}-\varepsilon_{1}}
\end{gathered}
$$

In listed equations $\alpha$ is the angle of the maximum residual stress from gauge number $1, \mathrm{~A}$ and $\mathrm{B}$ are materials constants that can be determined from the following equations 4 and 5 :

$$
\begin{aligned}
A & =-\frac{1+v}{2 E} a \\
B & =-\frac{1}{2 E} b
\end{aligned}
$$

where $a$ and $b$ are reduction coefficients, $v$ is Poisson's ratio and $E$ is elastic modulus. The coefficients $a$ and $b$ can be determine from ASTM standard E 837 [4].

\section{RESULTS AND DISCUSSION}

Residual stresses are determined in the depth of EDMed specimen at the discharge current levels of 3, 6, 9 and 12 ampere using hole-drilling method. The amount of maximum residual stresses at different depths are given in Table 3 and are shown in Figure 3.

The hole was drilled in six steps with an increment of $25 \mu \mathrm{m}$ until the depth of $150 \mu \mathrm{m}$. Tests are performed for all specimens by drilling with the same depth/increment. After measuring the va- lue of each strain gauge and computing the values of residual stresses. It is seen that tensile stresses are observed for all discharge currents near the EDMed surfaces which are converting into compressive stresses after some depth to balance the tensile stresses. Generally the amount of residual stresses is found proportional to the discharge current near the surface up to the depth of $75 \mu \mathrm{m}$. This observation is in agreement to [12], where it was found that thicker the white layer, EDM induced residual stresses for tool steel were higher. There are a number of research publications in which it is found that the thickness of the recast/white layer is proportional to discharge current and discharge energy as well $[10,20]$. This is because high discharge energy is produced with higher discharge current and hence higher will be the volume of the molten pool. Consequently the thickness of the resolidified unremoved material is more for relative high discharge current. When compared with

Table 3. Residual stresses (MPa) at different depths

\begin{tabular}{|c|c|c|c|c|c|}
\hline $\begin{array}{c}\text { Depth } \\
(\mu \mathrm{m})\end{array}$ & $3 \mathrm{~A}$ & $6 \mathrm{~A}$ & $9 \mathrm{~A}$ & $12 \mathrm{~A}$ & $\begin{array}{c}\text { Turned } \\
\text { specimen }\end{array}$ \\
\hline 25 & 22 & 23 & 30 & 33 & -93 \\
\hline 50 & 20 & 15 & 35 & 37.5 & -121 \\
\hline 75 & 17 & 17 & 26 & 31 & -56 \\
\hline 100 & -8 & 8 & 12 & 12 & -33 \\
\hline 125 & -3 & -7 & 3 & -15 & 7 \\
\hline 150 & -5 & -12 & -10 & -7 & 10 \\
\hline
\end{tabular}




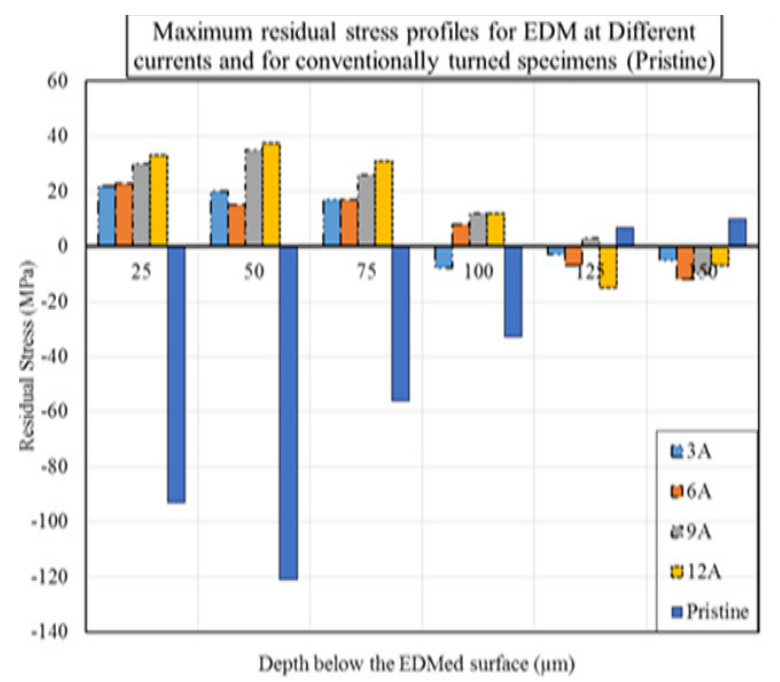

Fig. 3. Residual stress profiles in surface depth

the pristine specimens, prepared by conventional machining, the results were different. For pristine specimens compressive stresses were developed with magnitude to much larger than those in EDM. Also for pristine specimens, it is found that near the surface residual stresses are smaller reaching maximum value abruptly until the depth of $50 \mu \mathrm{m}$ and below that stresses went on vanishing. At the depth of $125 \mu \mathrm{m}$, the nature of residual stresses were converted to tensile. A previous study performed by Denkana [3] on wrought aluminum alloy conforms the outcome of current study for conventionally turned specimens.
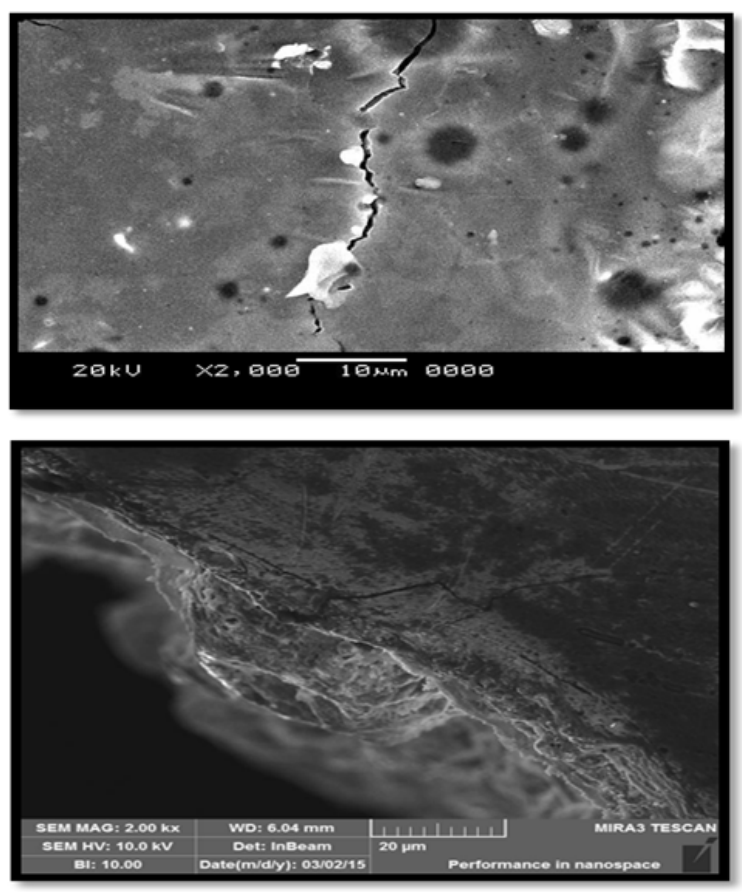

Fig. 4. SEM observations from top and side
Due to metallurgical changes in the white layer and high temperature effects in the lower region of the white layer, material degradation may occur. Tensile nature of residual stresses in addition to some other factors such as surface pits can cause cracking. As shown in Figure 4, it is seen that a crack is initiating from the white layer and is penetrating into the bulk material. Such situations are more threatening for the investigated material because of its numerous applications in aerospace industry. Also the generated surface after electric discharge machining is looking irregular and having a number of stress concentration sites. Energy dispersive spectroscopy (EDS) of the surface generated was also performed and it was recognized that the resolidified layer became highly contaminated with carbon and copper contents.

Changes in chemical composition of the surface layer as well as presence of residual stresses and morphological defects are possible sources of immature failure of machined components when subjected to fatigue loads. This needs further investigation to evaluate fatigue life behavior after EDM with respect to most important discharge current parameter.

\section{CONCLUSION}

Effect of electric discharge machining for the discharge current values which are mostly used for finish operation are investigated. Repeatedly high and rapid temperature changes can possibly induce residual stresses as were investigated by numerous studies for tool steel material. Very little such literature is available for aerospace grade aluminum alloy. As this material is used in high frequency and fatigue application where surfaces play a vital role in deciding its total life. Study of residual stresses is important as these stresses might be beneficial or detrimental and at what extent in reference to the most important machining parameter, i.e discharge current. Five discharge current levels are investigated and also residual stresses are determined for conventionally machined specimens for comparison. The effect of discharge current on the magnitude of residual stresses is clearly seen and concluded that these are of tensile nature irrespective of the discharge current level used during EDM machining. There is little effect of the discharge current, however this effect could not be ignored when other ma- 
terial/surface characterizing factors are also influencing with this parameter. It is therefore suggested that electric discharge machined surface should be removed or converted into beneficial compressive stresses.

\section{Acknowledgements}

This research work was funded and supported by the University of Engineering and Technology, Taxila under research grant no. FME-ME-250, which is highly acknowledged. Special thanks to Technopak Engineering Private ltd., for his technical and logistic support during sample preparation and Institute of Space Technology for scanning electron microscopy.

\section{REFERENCES}

1. Bussu, G. and P. Irving, The role of residual stress and heat affected zone properties on fatigue crack propagation in friction stir welded 2024-T351 aluminium joints. International Journal of Fatigue, 25 (1), 2003, 77-88.

2. Das, S., M. Klotz, and F. Klocke, EDM simulation: finite element-based calculation of deformation, microstructure and residual stresses. Journal of Materials Processing Technology, 142(2), 2003, 434-451.

3. Denkena, B. and L. de León, Machining induced residual stress in wrought aluminium parts. in Proceedings of 2nd International Conference on Distortion Engineering, Bremen, Germany, 2008, 107-114.

4. E837-08, A., "Standard Test Method for Determining Residual Stresses by the Hole Drilling Strain Gage method," ASTM Intrenational Conshohocken, PA2008.

5. Ekmekci, B., O. Elkoca, A. Erman Tekkaya, and A. Erden, Residual Stress State and Hardness Depth in Electric Discharge Machining: De-Ionized Water as Dielectric Liquid. Machining Science and Technology, 9(1), 2005, 39-61.

6. Ekmekci, B., A.E. Tekkaya, and A. Erden, A semiempirical approach for residual stresses in electric discharge machining (EDM). International Journal of Machine Tools and Manufacture, 46(7-8), 2006, 858-868.

7. Flaman, M. and B. Manning, Determination of residual-stress variation with depth by the holedrilling method. Experimental mechanics, 25(3), 1985, 205-207.

8. García Navas, V., I. Ferreres, J.A. Marañón, C. Garcia-Rosales, and J. Gil Sevillano, Electro-discharge machining (EDM) versus hard turning and grinding - Comparison of residual stresses and surface integrity generated in AISI O1 tool steel. Journal of Materials Processing Technology, 195(1-3), 2008, 186-194.

9. Guo, Y.B., W. Li, and I.S. Jawahir, Surface Integrity Characterization and Prediction in Machining of Hardened and Difficult-to-Machine Alloys: A State-of-Art Research Review and Analysis. Machining Science and Technology, 13(4), December, 2009, 437-470.

10. Herbert, C., D. Axinte, M. Hardy, and P.D. Brown, Investigation into the Characteristics of White Layers Produced in a Nickel-Based Superalloy from Drilling Operations. Machining Science and Technology, 16(1), 2012, 40-52.

11. Huang, X., J. Sun, and J. Li, Effect of Initial Residual Stress and Machining-Induced Residual Stress on the Deformation of Aluminium Alloy Plate. Strojniški vestnik-Journal of Mechanical Engineering, 61(2), 2015, 131-137.

12. Lee, H.-T., W.P. Rehbach, F.-C. Hsu, T.-Y. Tai, and E. Hsu, The study of EDM hole-drilling method for measuring residual stress in SKD11 tool steel. Journal of materials processing technology, 149(1), 2004, 88-93.

13. Lee, H. T. and T. Y. Tai, Relationship between EDM Parameters and Surface Crack Formation. Journal of Materials Processing Technology, 142(3), 12/10/ 2003, 676-683.

14. Micro-Measurements, V., "Measurement of residual stresses by the hole drilling strain gage method," Tech Note TN-503-62005.

15. Noyan, I.C. and J.B. Cohen, Residual stress: measurement by diffraction and interpretation: Springer-Verlag, 2013.

16. Olabi, A. and M. Hashmi, Stress relief procedures for low carbon steel (1020) welded components. Journal of materials processing technology, 56(1), 1996, 552-562.

17. Prevey, P.S., X-ray diffraction residual stress techniques. ASM International, ASM Handbook., 10(1986, 380-392.

18. Rossini, N.S., M. Dassisti, K.Y. Benyounis, and A.G. Olabi, Methods of measuring residual stresses in components. Materials \& Design, 35(3// 2012, 572-588.

19. Schajer, G., Measurement of non-uniform residual stresses using the hole-drilling method. Part I - Stress calculation procedures. Journal of Engineering Materials and Technology, 110(4), 1988, 338-343.

20. Shabgard, M., S.N.B. Oliaei, M. Seyedzavvar, and A. Najadebrahimi, Experimental Investigation and 3D Finite Element Prediction of the White Layer Thickness, Heat Affected Zone, and Surface Roughness in EDM Process. Journal of mechanical 
science and technology, 25(12), 2011, 3173-3183.

21. Shabgard, M., M. Seyedzavvar, and S.N.B. Oliaei, Influence of Input Parameters on the Characteristics of the EDM Process. Strojniški vestnik - Journal of Mechanical Engineering, 57(09), 2011, 689-696.

22. Srinivasa Rao, P., K. Ramji, and B. Satyanarayana, Effect of wire EDM conditions on generation of residual stresses in machining of aluminum 2014 T6 alloy. Alexandria Engineering Journal, 55(2), 6/2016, 1077-1084.
23. Zeilmann, R.P., T. Vacaro, F.M. Zanotto, and M. Czarnobay, Metallurgical alterations in the surface of steel cavities machined by EDM. Matéria (Rio de Janeiro), 18(4), 2013, 1541-1548.

24. Butt Z., Pasha R.A. and Qayyum F. Generation of electrical energy using lead zirconate titanate (PZT-5A) piezoelectric material: Analytical, numerical and experimental verifications. Journal of Mechanical Science and Technology, 30(8), 2016, $3553-3558$ 